\title{
KEY TECHNOLOGY OF CREEP MONITORING FOR ANCHOR STRUCTURE OF SUSPENSION BRIDGE
}

\author{
Cai Qian \\ Chongqing Technology and Business Institute, Chongqing 401520, China \\ E-mail:qagmoo@163.com
}

\begin{abstract}
To study the key technology of the creep monitoring of the anchor structure of suspension bridge, through the exploration of the application of tunnel anchorage at home and abroad and other related technologies, two sets of devices and methods of displacement detection of the anchorage structure are put forward. The composition of the two sets of devices is studied, and the steps and methods of the measurement are put forward. The accuracy, reliability and stability of the two sets of systems are tested by building a simulation platform. The displacement detection system of anchorage structure based on laser image analysis is designed. On this basis, the system realization scheme is put forward, and the related technologies are analysed in detail. In addition, the displacement detection system of anchorage structure based on displacement difference amplification is also designed. The improvement scheme is proposed based on the correction of the system error, and the measurement principle and characteristics of the improved scheme are analysed. A series of test experiments are designed and implemented on the two sets of systems by building a simulation test platform. The test purposes, conditions, equipment and process are introduced, respectively. The experimental demonstration of each system is proved and effective conclusions are obtained. Then, the performance of the two sets of systems is compared and analysed. The experimental results show that the two systems are able to measure the small displacement reliably. When the measurement range is $-10 \mathrm{~mm}-10 \mathrm{~mm}$, the relative error of the displacement detection system of the anchorage structure based on the laser image analysis can be controlled within $10 \%$.
\end{abstract}

Keywords: Suspension Bridge; Anchor Structure; Creep Monitoring; Displacement.

\section{Introduction}

With the rapid growth of the world economy in twenty-first Century, the longer and larger bridges are bound to be the goal of the bridge construction industry. The suspension bridge is recognized as one of the most important bridge forms in the long-span bridge. At present, most of the $1000 \mathrm{~m}$ span bridges over the world are the suspension bridges. Its obvious advantages in the structure force and construction method make it more and more widely adopted in the world [1]. With the implementation of the Central Committee's strategic decision on the development of the western region, many trunk roads will be built in the southwest of China. Because of the complicated terrain and the ravines in Southwest China, some cross-river bridges may adopt suspension bridge schemes. In the course of using long-span suspension bridges, the traffic loads are quite heavy, and occupy a very important position in the national economic construction [2].

When there is a strong rock stratum near the anchorage, the tunnel anchorage is the most economical and reasonable, so it has been widely valued and applied. However, in all the long-span suspension bridges at home and abroad, there is little that the geological conditions of the bridge site meet the standard of the tunnel anchor. All the records show that the only George in the United States applied the project of the tunnel anchor [3].

Chongqing Wanzhou Yangtze River bridge is the world's largest tunnel anchor use project among the anchorage of the West Bank of Washington Bridge, the San Francisco Oakland bridge, the two anchorages of the British Forth highway bridge, the anchorage of the Kvalsund bridge in Norway, the two anchorage of the Huo Jiateng stuca viaduct in central Sweden, the East anchorage of the Guangdong Humen bridge, the Chongqing Fengdu Yangtze River bridge, Chongqing Zhongxian Yangtze River bridge, and Chongqing Wanzhou Yangtze River bridge [4].

In China, the first proposed tunnel anchorage is in Guangdong Humen bridge. First, a discussion on "the quality assessment and engineering countermeasures for the rock mass of the East anchorage of the Humen bridge" was organized by the Institute of Geotechnical Engineering of the Tongji University, and a written document record was formed. The discussion is mainly about whether 
the Humen bridge chose tunnel anchors or gravity anchors and which type of structure has less influence on the stability of the surrounding rock.

The field simulation test is carried out on the application of the tunnel anchor [5]. By setting up 1:50 bridge body model, the deformation of the rock mass in the anchored area is observed under a certain load, the serious deformation area is shown and its causes are analysed. And through continuous loading increase, the indexes of bridges under the condition of critical failure are obtained. The study on tunnel anchor in Yangtze River bridge of Goose Rock in Chongqing is closely followed by the Humen bridge. It not only extends the analysis method of the stability of the anchorage structure and surrounding rock in the study of the Humen bridge, but also develops a complete set of analysis system, including the parameter study, the structural model test, and the numerical analysis. The scale of Yangtze River bridge of Goose Rock in Chongqing is larger (1:12.5), and the load added in the test is even higher, reaching 4.6 times the design load [6]. On the basis of summing up the previous research experience, the stability analysis of the tunnel anchorage and its surrounding rock has focused on the Sidu River Bridge, the Branch Well River Bridge and the Hunan Short-Village Bridge, which is still at the stage of the design and research [7]. In June 2005, China successfully realized the model test and analysis of the anchorage structure of the super large bridge of Sidu. In this experiment, the model scale is slightly increased than the Goose Rock Bridge (1:12).

The maximum load on the model also exceeds super Goose Rock Bridge, with more than 8 times of the design load [8].

Because of the less application of tunnel anchorage in practical engineering, the research literature on the method of creep displacement detection has not been consulted at present.

The general practice at home and abroad is to carry out the structure model experiment through some concrete engineering examples, and the deformation mechanism of anchorage and surrounding rock is obtained in the loading test of the model structure. Compared with Europe, the United States and Japan, the operation of the suspension bridge in China is a bit late, so it is difficult to find the relevant documents in China, not to mention the study literature of the method of detecting the peristaltic displacement of the tunnel type anchorage [9].

However, in the great trend of rapid development of China's modernization, under the same geological conditions, the tunnel anchor is no doubt a good choice to save the economy and protect the environment.

Therefore, it is of great practical significance to study and analyze the deformation characteristics of the tunnel anchor structure.

\section{Methodology \\ 2.1 Principle of displacement monitoring of laser projective structure of collimation point}

The system is extended on the basis of the displacement measurement of the collimated point laser projective structure.

The basic principle of the collimated point laser projective structural displacement monitoring technique is as follows: first, the laser is fixed on the measured object, the laser beam is emitted by the laser, and the laser beam is received by the remote fixed half transmission screen. As a result, a circular spot is formed on the receiving screen, as shown in Figure 1 . Then, the camera is placed in the proper distance from the rear of the receiving screen to collect the laser spot image at every moment, and the coordinates of the centre of the circular spot can be determined by the image processing technology.

When the peristaltic displacement $\Delta \mathrm{L}$ (the displacement $\Delta \mathrm{X}$ occurs in the $\mathrm{X}$ direction and the displacement $\Delta \mathrm{Y}$ occurs in the $\mathrm{Y}$ direction) is produced under the external load. The laser launcher is fixed on the structure to be measured, so it will move together with the structure to be measured, and the laser spot on the receiving screen also takes the same displacement $\Delta \mathrm{L}$ because it is collimated.

By connecting the camera with the industrial control computer, the laser spot image collected by the camera is transmitted to the industrial control machine, and the location of the spot centre is completed by the image processing technology.

The spot centre coordinate $(\mathrm{x} 0, \mathrm{y} 0)$ at a certain time is defined as the initial position, and the centre coordinate of the spot image at a certain time is recorded as (xi, yi).

From formula (1), the change of the spot centre in the $\mathrm{X}$ and $\mathrm{Y}$ directions corresponding to the initial moment can be obtained.

$$
\left(\Delta x_{i}, \Delta y_{i}\right)=\left(x_{i}, y_{i}\right)-\left(x_{0}, y_{0}\right)
$$

In (1), $\Delta x i=x i-x 0, \Delta y i=y i-y 0, \Delta x i$ suggests the displacement of the spot centre in the direction of $X$, and $\Delta y$ indicates the displacement of the centre of light in the direction of Y. The central displacement of the spot can be obtained by formula (2).

$$
\Delta \mathrm{L}_{i}=\sqrt{\left(\Delta x_{i}\right)^{2}+\left(\Delta y_{i}\right)^{2}}
$$

That is:

$$
\Delta \mathrm{L}_{i}=\sqrt{\left(x_{i}-x_{0}\right)^{2}-\left(y_{i}-y_{0}\right)^{2}}
$$




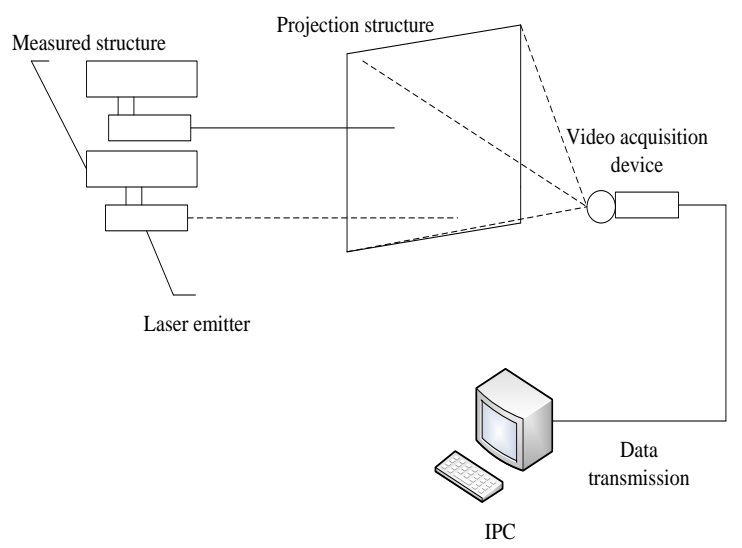

Figure 1: Schematic diagram of displacement monitoring for collimating point laser projection structure

\subsection{Displacement monitoring principle of anchorage structure based on laser image analysis}

Considering the complexity of the tunnel anchorage structure, the laser monitoring technology for the anchored structure is different.

This system is improved on the basis of the collimation point laser projection. Firstly, the laser transmitter and the laser receiving target position are replaced, and the installation position of the laser transmitter is not displaced in this system.

The laser receiving target is mounted on the peristaltic anchorage structure and then moves together. Secondly, the laser beam does not shoot the target vertically, but irradiated to the target with a certain angle $\theta$, as shown in Figure 2 .

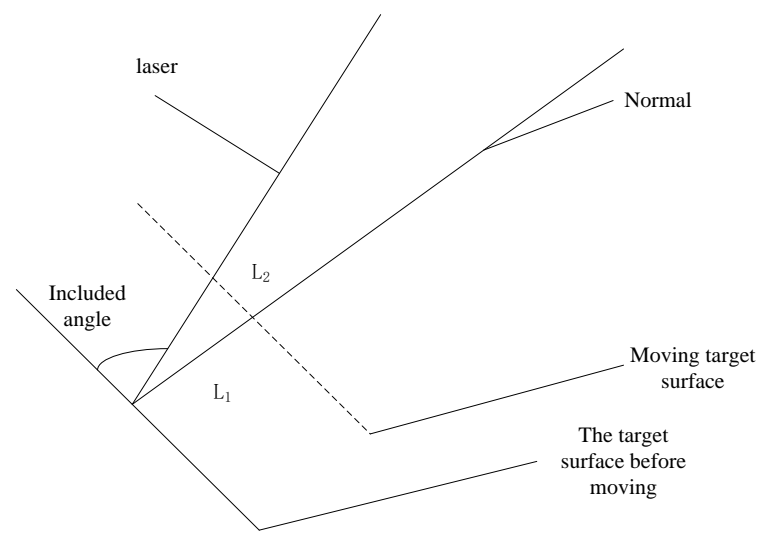

Figure 2: Schematic diagram of the laser spot before and after moving the target

Figure 2 is a schematic diagram of the structure of a laser spot before and after the target is moved.

The $X$ coordinates are anchor horizontal direction, the $\mathrm{Y}$ coordinates are anchor vertical direction, and the $\mathrm{Z}$ coordinates are perpendicular to the anchorage plane.
Only the displacement of the anchorage zone in the direction of $\mathrm{Z}$ is taken into account. The laser irradiates to the laser spot receiving target with a certain angle $\theta$ to form a spot, collects the video signal of the spot receiving target, and obtains the current spot video image. Through formula (1), the change amount $2 \mathrm{~L}$ in the direction of $\mathrm{Y}$ before and after the spot centre position is moved can be obtained, and the displacement $2 \mathrm{~L}$ of each collection is substituted into the formula.

$$
\mathrm{L}_{1}=\mathrm{L}_{2} \operatorname{tg} \theta
$$

That is:

$$
\mathrm{L}_{1}=\sqrt{\left(x_{i}-x_{0}\right)^{2}-\left(y_{i}-y_{0}\right)^{2}} \operatorname{tg} \theta
$$

The displacement L1 of the laser spot receiving target in the $\mathrm{Z}$ direction is calculated. In this system, because the laser line is irradiated with a certain angle of $\theta$ to the target, the displacement response of the target in the $\mathrm{Z}$ direction in the light spot is the displacement occurred in the $\mathrm{Y}$ direction.

\subsection{System measurement principle}

The design of the device for increasing the reference piston component not only corrects the influence of environmental factors on the measurement results, but also simplifies the reading method of monitoring data.

The principle of the improved method is: the two sets of components are placed in the places where displacement almost does not occur or the displacement is unknown in the anchoring room with a fixed support. As the piston assembly is fixed on the surface of the anchorage zone through the piston connection rod, the first live piston in the piston assembly is measured when the anchorage zone is subjected to the change of the force before and after the creep. The piston 8 moves with it (the first piston 8 moving displacement of the first liquid container 6 is $\mathrm{Li}$ ), and then affects the change of the liquid height in the first glass tube 7 in the piston assembly (the height of the first glass tube 7 is L1). Due to the invariance of the tensile / compression volume of the fixed liquid, the change of the liquid volume in the first liquid container 6 (the inner diameter of the first liquid container 6 is D) is equal to that in the first glass tube 7 (the inner diameter of the first liquid container 7 is $\mathrm{d}$ ), that is:

$$
\pi D^{2} L_{i}=\pi d^{2} L_{1}
$$

The reference piston assembly, in addition to the non-piston connecting rod, is connected to the anchorage zone, and the other is exactly the same as the piston assembly. 
Under the same condition, the liquid in the two components will cause the same change in the height of the liquid surface in the first and second glass tubes due to heat expansion and cold contraction (the height of the inner liquid of the second glass tube 14 is L2). Then, the above formula is changed into:

$$
\pi D^{2} L_{i}=\pi d^{2}\left(L_{1}-L_{2}\right)
$$

In the above formula, L1-L2 is the actual change in the height of the first glass tube 7 caused by the correction of the temperature, so the actual displacement of the first piston 8 (i.e., the displacement of the anchorage zone in the direction of the force) is:

$$
L_{i}=\left(L_{1}-L_{2}\right) d^{2} / D^{2}
$$

In order to easily collect the height of the liquid surface, a layer of colored and insoluble organic matter can be covered on the liquid surface of the glass tube. The method also includes the image acquisition instrument and the industrial control machine, and the image acquisition instrument is connected with the industrial control machine to realize the real-time data receiving and the longterm data storage.

The image collection instrument is used to capture the height of the liquid surface, and the industrial control machine is used for the real-time receiving, monitoring, long-term storage and analysis of the transmission data of the image acquisition instrument.

The industrial control machine is connected by Internet or mobile communication network to realize the remote data monitoring, storage and analysis.

\section{Results and Discussion}

\subsection{Displacement detection system test for anchorage structure based on laser image analysis}

The displacement detection system of anchorage structure based on laser image analysis is carried out in a university electronic laboratory, as shown in Figure 3 below. In the test, the displacement test experiment is carried out by the self-designed simulated anchorage structure, the feasibility of the method is verified by means of experiment, and the stability and accuracy of the method are confirmed.

The test of creep displacement of anchorage structure is carried out according to the following steps. In this experiment, the influence of temperature on the measurement results is not taken into account, and no external vibration is guaranteed as far as possible.

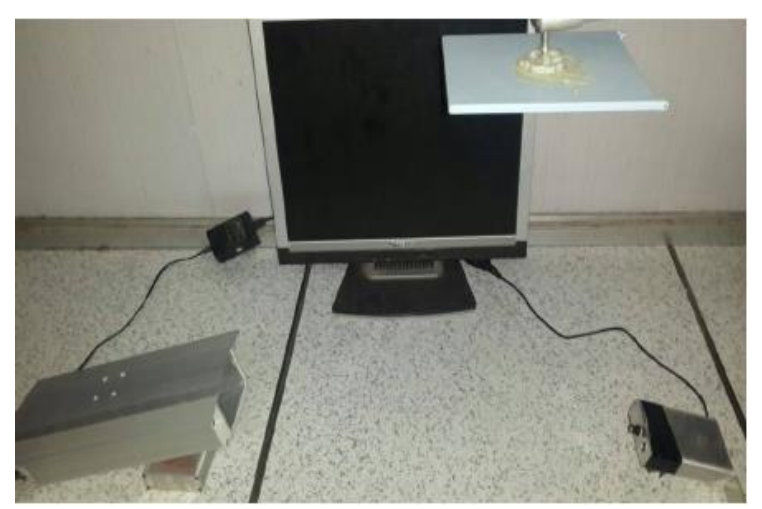

Figure 3: Displacement detection system for anchorage structure based on laser image analysis

First, select the appropriate position to place the anchorage structure, install the laser receiving target on the structure, fix the laser launcher at the 60$80 \mathrm{~cm}$ of the structure, and install the reflector fixed above the anchorage structure and the laser launcher, as shown in Figure 3. Second, open the light irritant, start the laser spot image acquisition and positioning software, and adjust the laser light, reflector and laser spot receiving target position, so that the laser irradiates the laser spot receiving target at a certain angle after the reflector is reflected. Third, use angle measuring instrument to measure the angle $\theta \quad(\theta=58.750)$ on the target irradiated by the laser, calibrate the pixel equivalent $\mathrm{k} 1$ and $\mathrm{k} 2(\mathrm{k} 1=0.0534, \mathrm{k} 2=0.0848)$ of the system, and set up and store in the acquisition software system. Fourth, detect the images manually under the stable system structure, get the initial coordinates of the spot center and save the setting. Fifth, after the initial coefficient setting is completed, measure the creep displacement of the anchorage structure: from $0 \mathrm{~mm}$, move the anchorage structure forward step by step to $10 \mathrm{~mm}$, each level of $1 \mathrm{~mm}$, detect the images manually after each level maintains for 3 minutes, and record the center coordinates of the spot.

After all the data are recorded, restore the anchorage structure to the initial position, and move the anchorage structure backward to with the same method, and record the related data. Sixth, repeat the fifth step for 3-4 times to ensure the reliability and stability of the data. 
Table 1 Anchorage forward movement experiment

\begin{tabular}{|c|c|c|c|c|c|c|c|}
\hline $\begin{array}{c}\text { Anchorage } \\
\text { displacement (mm) }\end{array}$ & $\begin{array}{c}\text { Spot } \\
\text { center X }\end{array}$ & $\begin{array}{c}\text { Spot } \\
\text { center Y }\end{array}$ & $\begin{array}{c}\text { Offset } \\
\text { pixel X }\end{array}$ & $\begin{array}{c}\text { Offset } \\
\text { pixel Y }\end{array}$ & $\begin{array}{c}\text { Offset } \\
\text { displacement } \\
\text { X (mm) }\end{array}$ & $\begin{array}{c}\text { Offset } \\
\text { displacement } \\
\text { Y (mm) }\end{array}$ & $\begin{array}{c}\text { Calculated } \\
\text { displacement } \\
(\mathrm{mm})\end{array}$ \\
\hline 0 & 356.3888 & 367.9008 & 0 & 0 & 0 & 0 & 0 \\
\hline 1 & 356.5277 & 361.7836 & -0.138 & 6.117 & -0.0074 & 0.5188 & 0.8547 \\
\hline 2 & 357.9748 & 353.8353 & -1.586 & 14.06 & -0.0847 & 1.1926 & 1.9654 \\
\hline 3 & 370.5706 & 345.8856 & -14.18 & 22.02 & -0.7573 & 1.8671 & 3.0765 \\
\hline 4 & 353.3026 & 340.2947 & 3.087 & 27.61 & 0.1647 & 2.3409 & 3.8576 \\
\hline 5 & 354.5778 & 330.3967 & 1.811 & 37.50 & 0.0966 & 3.1805 & 5.2408 \\
\hline 6 & 361.0761 & 325.3378 & -4.687 & 42.56 & -0.2504 & 3.6094 & 5.9477 \\
\hline 7 & 353.2352 & 317.1957 & 3.153 & 50.71 & 0.1685 & 4.2999 & 7.0855 \\
\hline 8 & 354.1699 & 305.9722 & 2.221 & 61.93 & 0.1186 & 5.2515 & 8.655 \\
\hline 9 & 357.4637 & 301.5392 & -1.075 & 66.36 & -0.0575 & 5.6276 & 9.2736 \\
\hline 10 & 357.1922 & 296.4303 & -0.803 & 71.47 & -0.0432 & 6.0606 & 9.9875 \\
\hline
\end{tabular}

Table 2 Anchorage backward movement experiment

\begin{tabular}{|c|c|c|c|c|c|c|c|}
\hline $\begin{array}{c}\text { Anchorage } \\
\text { displacement(mm) }\end{array}$ & $\begin{array}{c}\text { Spot } \\
\text { center X }\end{array}$ & $\begin{array}{c}\text { Spot } \\
\text { center Y }\end{array}$ & $\begin{array}{c}\text { Offset } \\
\text { pixel X }\end{array}$ & $\begin{array}{c}\text { Offset } \\
\text { pixel Y }\end{array}$ & $\begin{array}{c}\text { Offset } \\
\text { displacement } \\
\text { X (mm) }\end{array}$ & $\begin{array}{c}\text { Offset } \\
\text { displacement } \\
\text { Y (mm) }\end{array}$ & $\begin{array}{c}\text { Calculated } \\
\text { displacement } \\
\text { (mm) }\end{array}$ \\
\hline 0 & 356.3888 & 367.9008 & 0 & 0 & 0 & 0 & 0 \\
\hline 1 & 357.9246 & 375.3223 & 1.536 & 7.422 & 0.0819 & 0.6292 & 1.0372 \\
\hline 2 & 356.4733 & 381.6143 & 0.085 & 13.71 & 0.0046 & 1.1628 & 1.9165 \\
\hline 3 & 349.6809 & 388.0472 & -6.708 & 20.15 & -0.3583 & 1.7085 & 2.8154 \\
\hline 4 & 362.9486 & 397.8224 & 6.558 & 29.92 & 0.3502 & 2.5375 & 4.1814 \\
\hline 5 & 361.4133 & 402.8717 & 5.024 & 34.97 & 0.2684 & 2.9655 & 4.8868 \\
\hline 6 & 364.3214 & 410.4269 & 7.933 & 42.53 & 0.4235 & 3.6064 & 5.9427 \\
\hline 7 & 348.5706 & 418.0166 & -7.953 & 50.12 & -0.4246 & 4.2499 & 7.0034 \\
\hline 8 & 356.6362 & 424.7039 & -7.818 & 56.80 & -0.4176 & 4.8170 & 7.9379 \\
\hline 9 & 356.4019 & 433.3512 & 0.246 & 65.45 & 0.0133 & 5.5501 & 9.1464 \\
\hline 10 & 356.3572 & 440.3953 & 0.013 & 72.49 & 0.0008 & 6.1476 & 10.1305 \\
\hline
\end{tabular}

It can be seen from Tables 1 and 2 that when the measurement range is $-10 \mathrm{~mm}-10 \mathrm{~mm}$, the maximum error of the measurement method is $0.9 \mathrm{~mm}$, the average error is $0.5 \mathrm{~mm}$, and the measurement precision can reach $0.1 \mathrm{~mm}$. Thus, the displacement measurement based on the laser image analysis can realize the detection of the small displacement.

The actual displacement of the anchor chamber and the measured displacement are fitted by the curve.
The small squares in the figure represent the measured displacement values, as shown in Figure 4.

It can be seen from Figure 4 that the displacement measured by this method is very close to the actual displacement value, and the correlation coefficient reaches 0.9996 . Therefore, it is envisaged that in the ideal environment, the displacement detection system of anchorage structure based on laser image analysis can truly reflect the creep state of the anchorage structure.

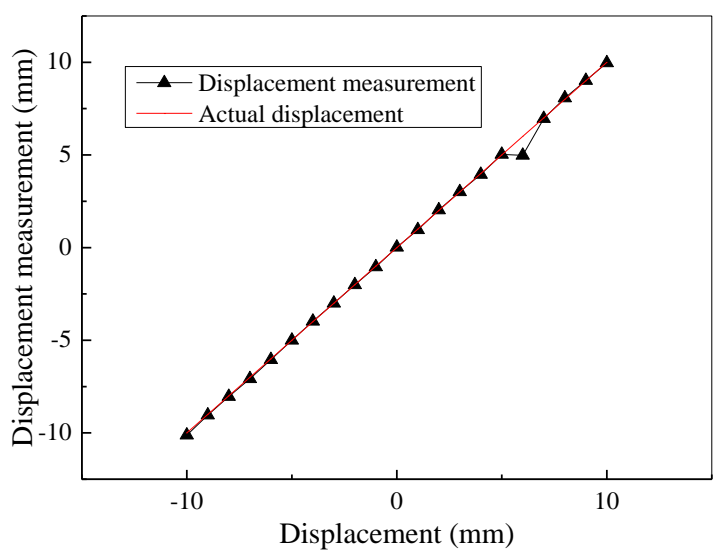

Figure 4: Comparison between actual displacement and measured displacement based on laser image analysis technology 


\subsection{Displacement detection system test for anchorage structure based on displacement difference amplification}

Because of the limited conditions, a simple simulation platform is built only in a university electronic laboratory. In the experiment, the inner diameter $\mathrm{R}$ of the syringe tube is $15 \mathrm{~mm}$, the inner diameter $r$ of the tube is $3 \mathrm{~mm}$, and the fixed distance of the two tubes is $153 \mathrm{~mm}$. The liquid level in the capillary tube of the piston assembly is measured as D1, the liquid surface displacement as L, and the liquid level in the thin tube of the reference piston assembly is recorded as D2.

Experimental steps: first, the syringes and tubes are connected, a proper amount of red liquid is injected into the syringes and tubes, and the two sets of piston assemblies are fixed in parallel to the smooth surface to ensure that the device will not move during the whole experiment.

Second, the initial position of the red liquid in the two pipe is calibrated to ensure that they are on the unified scale line. One of the devices is selected as the reference piston assembly and the other is the piston assembly.
Third, pre-extrusion is completed: starting from the initial position $0 \mathrm{~mm}$, the piston assembly in the piston assembly is pressed forward step by step to $10 \mathrm{~mm}, 1 \mathrm{~mm}$ at each level. After 3 minutes of each stage, the measurement, recording of D1D2 and the height variation $L$ of the pipe level are completed.

After the extrusion piston displacement reaches $10 \mathrm{~mm}$, continue for 3 minutes and recover to the initial position. Observe the measured value and the calculated value of the height change of the tube level in the observation test.

Through the analysis of the difference data of the measured value and the calculated value, determine whether the temperature of the system equipment reaches the requirement of the effective experimental demonstration. If so, carry out the next step of formal extrusion / tensile test.

In the next table, D1D2 is the distance of the two pipes level. $L$ is the actual measurement value of the height change of the tube level in the component. $\mathrm{L}^{*}$ is the theoretical calculation of the height variation of the tube level in the component (calculated by Pythagorean of the values of D1D2 and D). S is the piston displacement calculated by $\mathrm{L}$, and $\mathrm{S}^{*}$ is the piston displacement calculated through $\mathrm{L}^{*}$.

Table 3 Pre-extrusion test data record

\begin{tabular}{|c|c|c|c|c|c|}
\hline Extrusion displacement $(\mathrm{mm})$ & $\mathrm{D}_{1} \mathrm{D}_{2}(\mathrm{~mm})$ & $\mathrm{L}(\mathrm{mm})$ & $\mathrm{L}^{*}(\mathrm{~mm})$ & $\mathrm{S}(\mathrm{mm})$ & $\mathrm{S}^{*}(\mathrm{~mm})$ \\
\hline 1 & 155.04 & 25.00 & 25.03 & 1.00 & 1.00 \\
\hline 2 & 161.09 & 51.48 & 50.37 & 2.05 & 2.02 \\
\hline 3 & 170.59 & 77.65 & 75.43 & 3.10 & 3.03 \\
\hline 4 & 182.61 & 103.51 & 99.66 & 4.13 & 3.99 \\
\hline 5 & 198.72 & 131.05 & 126.78 & 5.25 & 5.06 \\
\hline 6 & 217.01 & 158.58 & 153.87 & 6.34 & 6.15 \\
\hline 7 & 231.02 & 178.96 & 173.09 & 7.15 & 6.91 \\
\hline 8 & 231.02 & 206.24 & 199.20 & 8.25 & 7.96 \\
\hline 9 & 251.17 & 227.48 & 220.35 & 9.10 & 8.80 \\
\hline 10 & 268.28 & 254.68 & 246.51 & 10.21 & 9.85 \\
\hline
\end{tabular}

From Table 3, it can be seen that the actual measurement value $\mathrm{L}$ and the theoretical calculation value $\mathrm{L}^{*}$ gap change process in the pre-extrusion process of measuring the height of the tube level in the component is: it first gradually increases and then tends to stability, as shown in Figure 5.

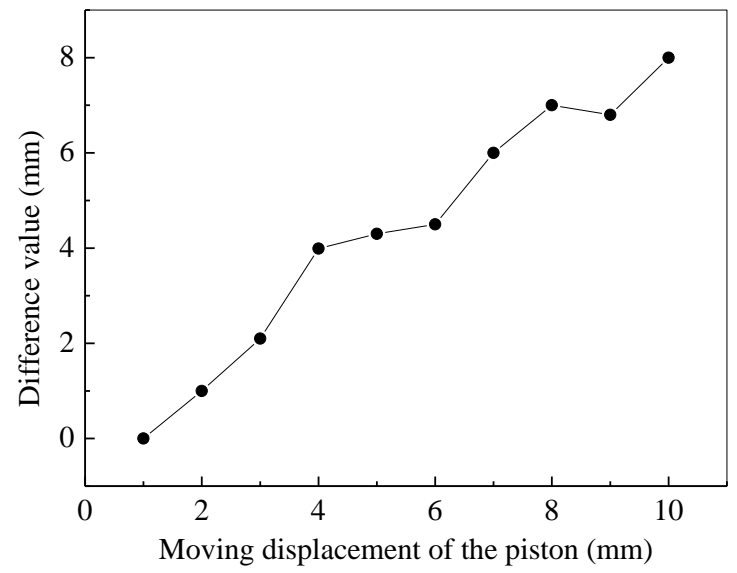

Figure 5: Comparison between measured values and calculated values of liquid level in thin tubes during preextrusion 
The cause of the change shown in Figure 5 is that the initial temperature (8 DEG C) used in the experiment is lower than the ambient temperature (16 DEG C). In the experiment, the liquid temperature gradually approaches the room temperature.

The thermal expansion of the liquid leads to the increase of the height of the liquid surface. Therefore, the measurement value $L$ is the superposition of the piston displacement and the thermal expansion of the liquid, and the theoretical calculation value $L^{*}$ is the true value after the thermal expansion error of the liquid is corrected, which is the temperature compensation function of the reference piston in the system.

\subsection{Comparative analysis}

The relative error between the measured value and the actual value of the displacement measurement method based on the laser image analysis technique can be calculated by Tables 1 and 2. The fitting curve is made for the relative error data, as shown in Figure 6.

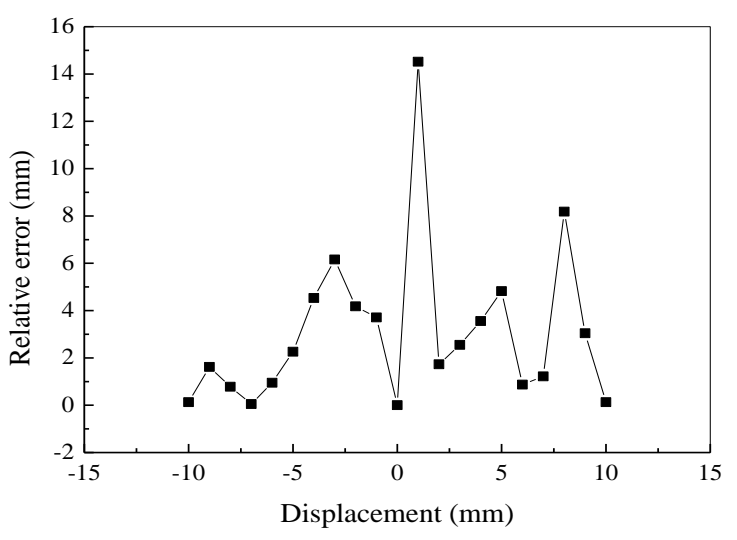

Figure 6: Relative error fitting curve of displacement measurement method based on laser image analysis technology

The relative error between the measured value and the actual value of the displacement measurement method based on the difference amplification technique can be calculated from the data in Figure 6 , as shown in Table 4.

The fitting curve is made for the relative error data of Table 4, as shown in Figure 7.

Table 4 Relative error of displacement difference amplification technology

\begin{tabular}{|c|c|c|c|c|c|}
\hline $\begin{array}{c}\text { Actual } \\
\text { displacement } \\
(\mathrm{mm})\end{array}$ & $\begin{array}{c}\text { Calculated } \\
\text { displacement } \\
(\mathrm{mm})\end{array}$ & $\begin{array}{c}\text { Relative } \\
\text { error }\end{array}$ & $\begin{array}{c}\text { Actual } \\
\text { displacement } \\
(\mathrm{mm})\end{array}$ & $\begin{array}{c}\text { Calculated } \\
\text { displacement } \\
\text { (mm) }\end{array}$ & $\begin{array}{c}\text { Relative } \\
\text { error }\end{array}$ \\
\hline 1 & 1.00 & 0 & -1 & -1.00 & 0 \\
\hline 2 & 2.00 & 0 & -2 & -2.00 & 0.02 \\
\hline 3 & 3.02 & $0.85 \%$ & -3 & -3.00 & 0.05 \\
\hline 4 & 4.05 & $1.48 \%$ & -4 & -4.02 & 0.12 \\
\hline 5 & 5.07 & $1.63 \%$ & -5 & -5.98 & 0.35 \\
\hline 6 & 6.09 & 1.72 & -6 & -7.02 & 0.15 \\
\hline 7 & 7.18 & 2.84 & -7 & -7.95 & 0.15 \\
\hline 8 & 7.84 & 2.42 & -8 & -9.04 & 0.82 \\
\hline 9 & 9.25 & 2.87 & -9 & -10.12 & 0.55 \\
\hline 10 & 10.22 & 2.29 & -10 & 0.38 \\
\hline
\end{tabular}

As can be seen from Figure 7, the relative error of the displacement measurement method based on laser image analysis technology fluctuates greatly and relatively high.

The cause of this error is that the dynamic acquisition process used in this method is sensitive to the change of the experimental environment and there is a relatively large vibration at the error value of $14 \%$.

According to Figure 6, the relative error of the displacement measurement method based on the difference amplification technology can be controlled within 5\%. The error distribution in the whole measurement process is stable. The cause of these small errors is that all the measurement readings in the system are observed by the human eye; the system equipment is simpler and has great influence on the measurement results.

Through the analysis of the experimental data of the above two methods, in general, the two methods can detect the micro displacement of the anchorage structure. 


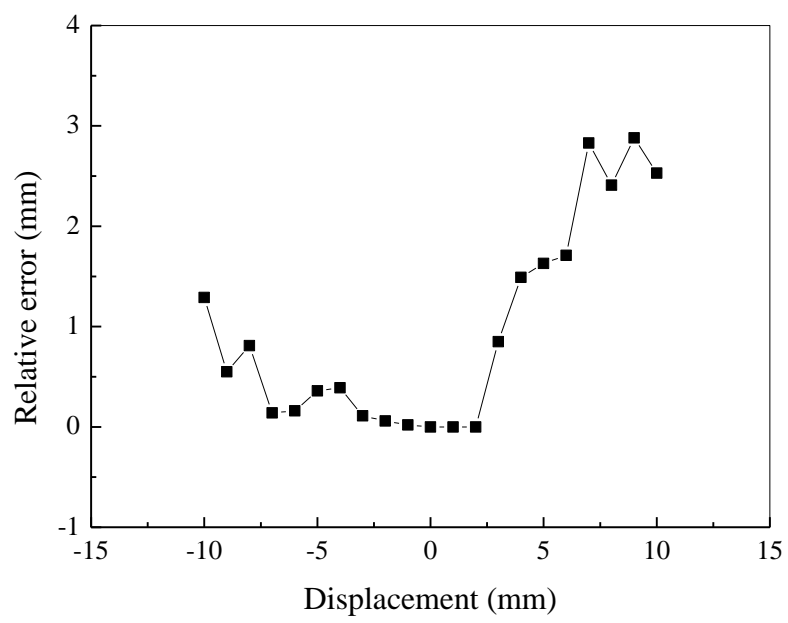

Figure 7: Relative error fitting curve of displacement measurement method based on difference amplification technology

\section{Conclusion}

Anchorage as one of the main load-bearing structures of suspension bridge, its overall stability and stress state directly affect the safety and normal use of the bridge.

After water storage in the Three Gorges Reservoir area, the complex stress field and seepage field of the water erosion environment will reduce the stability of the tunnel anchor and surrounding rock, change the stress and deformation of the anchorage, and cause the cracking and deflection of the anchorage (anchor hole), the corrosion of the anchor head and the scattered cable saddle and so on. Then, it will further affect the operational safety of the bridge structure.

In order to prevent the damage of the bridge structure due to too great deformation, it is necessary to conduct the long-term displacement monitoring of the anchorage structure.

The displacement of the anchorage structure is an important element of the health monitoring of the bridge structure. It is one of the important indexes to evaluate the function and safety of the bridge and it directly reflects the overall stiffness of the bridge structure.

First of all, the research status of tunnel anchorage at home and abroad is summarized, and that there is no relevant literature on the displacement detection of anchorage structure is pointed out.

Then, two sets of displacement monitoring system for the tunnel anchorage structure of suspension bridge under water erosion environment in the Three Gorges Reservoir area are put forward displacement detection device and method for anchorage structure based on laser image analysis and displacement detection device and method for anchorage structure based on displacement difference amplification.
The main conclusions are as follows: a displacement detection system of anchorage structure based on laser image analysis is proposed.

Through special device design, this system transforms the displacement of the center coordinates of the spot on the target of the anchorage surface to the displacement of the anchorage, and puts forward a displacement detection system based on the displacement difference amplification.

Through the piston extruding / drawing the liquid in the large inner diameter container to the small inner diameter pipe, the change of the liquid height in the tube before and after the extruding / drawing is compared, and the displacement of the anchorage structure is indirectly calculated.

\section{Acknowledgements}

The authors acknowledge the National Natural Science Foundation of China (Grant: 111578109), the National Natural Science Foundation of China (Grant: 11111121005).

\section{References}

[1] Rong L X, Liang L D, Chao W X, et al (2017). Filed model tests on bearing behavior of mudstone tunnel anchorage. Chinese Journal of Geotechnical Engineering, 39(1), 161-169.

[2] Li Y, Luo R, Zhang Q, et al (2017). Model test and numerical simulation on the bearing mechanism of tunnel-type anchorage. Geomechanics \& Engineering, 12(1), 139-160.

[3] Xiao W, Yong-Hua S U, Fang Y B, (2016). Anchorage mechanical effect of tunnel surrounding rock considering post-peak characteristics. Journal of Highway \& Transportation Research \& Development, 11(1), 49-58. 
[4] Pedersen F M, Christensen S C, Jacobsen J S, et al (2015). Izmit bay suspension bridge - main cable anchorages. 105(1), 1-8.

[5] Ding W, Liu J, Zhang L, et al (2016). Analysis on interaction of rock-bolts in anchorage support structure of subsea tunnel at different corrosion levels. Journal of Central South University, 45(5), 1642-1652.

[6] Qin D, Hua T, Zhen J, et al (2017). Research on capacity characteristics of tunnel anchorage and distortion correction. Rock \& Soil Mechanics, 38(11), 247-254.
[7] Wen L N, Cheng Q G, Cheng Q, et al (2017). Deformation experiment research on the model tunnel anchorage of dadu river bridge in luding. Journal of Railway Engineering Society, 34(1), 5259.

[8] Wang X, Kang J, Sui C E. (2015). Reliability analysis of the tunnel liner pre-stressed with circumferential un-bonded tendons based on the monitoring data. Journal of Hydroelectric Engineering, 34(2), 144-148.

[9] Li H, Zhang B, Liu J, et al (2017). The bolting parameters of the secondary support in coal mine tunnel. Journal of Mining \& Safety Engineering, 34(5), 962-967.

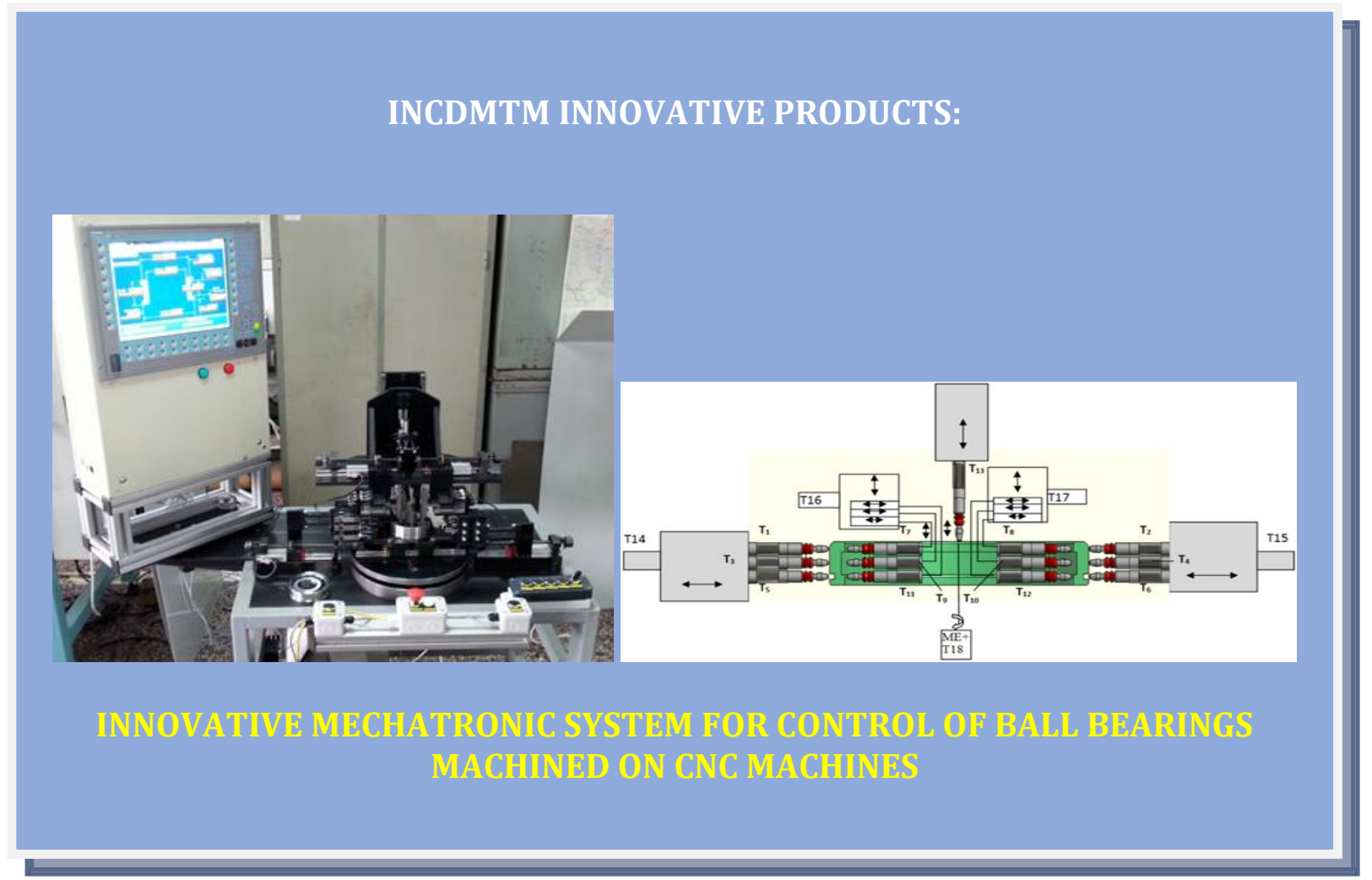

